\title{
Wedge Impact with the Influence of Ice
}

\author{
Yang Chen ${ }^{\mathrm{a}, *}$, Tatyana Khabakhpasheva ${ }^{\mathrm{b}}$, \\ Kevin J. Maki ${ }^{\mathrm{a}}$, Alexander Korobkin ${ }^{\mathrm{b}}$ \\ ${ }^{a}$ Department of Naval Architeture and Marine Engineering, University of Michigan, \\ Ann Arbor, Michigan, 48109, USA \\ ${ }^{b}$ School of Mathematics, University of East Anglia, Norwich, UK
}

\begin{abstract}
This work presents a canonical study on a wedge entering water near a single piece of ice using computational-fluid-dynamics (CFD) and a Wagner-type theoretical model with corrections for non-linear effects. Calculations for a series of conditions with ice of different sizes and locations relative to the wedge are conducted. The hydrodynamic force due to impact, the pressure distribution on the wedge surface, and the pile-up phenomenon are examined to study the role of ice in the impact process. The theoretical model is shown to be accurate and can serve as a useful method to assess slamming loads under the influence of ice. It is shown that even for the case of a small piece of ice, the slamming force on the wedge can increase by $30 \%$.

Keywords: Water Entry, Wedge impact with ice, Computational fluid dynamics
\end{abstract}

\section{Introduction}

The access to open water in the Arctic is steadily increasing. Expanded marine operations are certain in the near future in this region due to the considerable interests for multiple industries. International sea transportation can 5 take advantage of the much shorter sea routes by entering the Arctic (Hong, 2012). In addition, the Arctic is estimated to contain considerable amount of

\footnotetext{
* Corresponding author

Email address: chanyang@umich.edu (Yang Chen)
}

Preprint submitted to Applied Ocean Research

May 7, 2019 
natural resources including oil, gas and minerals (Borgerson, 2008). Challenges also exist due to the lack of infrastructures along the Arctic region and the harsh environment (Farré et al., 2014). International Maritime Organization (IMO) and classification societies have developed specific rules for vessels that intend to operate in the polar region. In early 2017, the IMO polar code was put in force (International Maritime Organization (IMO), 2017).

Transit through the Arctic exposes a ship to different types of icy conditions and the most severe storms that occur on earth. This requires extension of traditional naval engineering knowledge to be able to properly account for the influence of the unique aspects of the arctic environment. As the ice has receded in recent years, large waves have recently been recorded in the Arctic due to the longer fetch for waves to grow. It is expected that stronger sea waves in the Arctic will be seen in the near future (Thomson and Rogers, 2014). The unique sea conditions in the Arctic make the ship-wave-ice interaction and water impact more relevant than ever. Water impact is an important phenomenon that can result in large impulsive loads and has important implications for the vessel operating speed and stability (Korobkin, 1996; Abrate, 2011).

Water impact due to the slamming motion of vessels has been extensively studied in recent years. Building on the work by von Karman (1929) and Wagner (1932), significant progress has been made toward understanding the role of large deadrise angles (Korobkin, 2004; Mei et al., 1999), geometric asymmetries (Judge et al., 2004; Semenov and Iafrati, 2006), three-dimensional effects (Sun and Wu, 2013; Scolan and Korobkin, 2001) and hydroelastic phenomena (Khabakhpasheva and Korobkin, 2013). In addition to these theoretical models, computational models which can provide more detailed data, have been applied to study water impact problems (Maki et al., 2011; Piro and Maki, 2013; Fairlie-Clarke and Tveitnes, 2008; Facci et al., 2016, 2015). Experiments have also been conducted to support the theoretical and computational find35 ings (Tveitnes et al., 2008; Wu et al., 2004; Jalalisendi et al., 2015). However, there is no previous study on slamming load with the influence of ice (part of this work has been presented in (Khabakhpasheva et al., 2018)), and as will be 
shown in this work, the presence of ice can have important effect on the impact load. Previous studies related to ship performance in a sea way with ice have been mostly focused on the ice load and operation in level ice (Su et al., 2010; Zhou et al., 2016), where violent motions such as slamming are not examined.

This work is specifically focused on deepening the understanding of how ice influences the slamming loads of a ship that is operating in the proximity of broken ice. We seek to provide insight on the effects of the size and location of the ice for future research on ships operating in the Arctic environment. This paper presents a combined theoretical and numerical study of a wedge entering the water with constant velocity near a single piece of ice while the ice is fixed in space. Test cases with ice of different size and location relative to the wedge are studied.

The rest of the paper is organized as follow. In Section 2, we describe the canonical problem studied in this work. The details of the CFD approach and the theoretical model are described in Section 3. In Section 4, results from both the CFD and the theoretical model are presented, which include the overall force experienced by the wedge, the pile-up dynamics, the pressure distribution on the wedge, and the free-surface evolution. Conclusions of the study and an outlook on future work are presented in Section 5 .

\section{Formulation of the problem}

The hydrodynamic problem due to a two-dimensional wedge entering the water surface is studied in this work. The fluid is considered to be incompressible. The geometry of the problem and the important parameters are defined in Fig. 1. A fixed Cartesian reference frame is defined with the $y$-axis along the vertical direction and $x$-axis along the horizontal direction. The origin of the reference frame is located at the intersection of the wedge apex and the calm water surface at the initial impact time. The width and the deadrise angle of the wedge are defined respectively as $B$ and $\beta$. The vertical distance between the chine and the apex of the wedge is $y_{\mathrm{ch}}$. The distance travelled by the wedge is 
designated as $y_{\mathrm{cw}}$. The horizontal distance between the centerline of the wedge and the jet root on each side of the wedge is defined respectively as $c_{l}$ and $c_{r}$. The subscripts $l$ and $r$ denote respectively the values of the left and right side of the wedge. $c^{*}$ is the horizontal reference length measured from the wedge centerline to the intersection of the calm water surface and the wedge. It is related to the wedge deadrise angle and the distance that the wedge has travelled as $c^{*}=y_{c w} \tan \beta$. A pile-up coefficient $C_{\mathrm{w}}$ can be defined as: (Facci et al. (2016))

$$
C_{\mathrm{w}}=\frac{c}{c^{*}}
$$

The length and thickness of the ice are defined respectively as $L$ and $\tau$. The distance between the ice and the centerline of the wedge is denoted as $x_{\mathrm{s}}$. The top surface of the ice is aligned with the calm water surface.

The impact takes place at time $t=0$. The wedge travels with a constant vertical velocity $V$. The fluid is considered to be laminar and incompressible. The flow field is assumed to be governed by the incompressible Navier-Stokes so equations:

$$
\begin{aligned}
& \nabla \cdot \mathbf{u}=0 \\
& \frac{\mathrm{D}(\rho \mathbf{u})}{\mathrm{D} t}=-\nabla p+\nabla \cdot\left[\mu\left(\nabla \mathbf{u}+\nabla \mathbf{u}^{\mathrm{T}}\right)\right],
\end{aligned}
$$

where $\mathbf{u}$ is the fluid velocity, $\rho$ and $\mu$ are the fluid density and dynamic viscosity; $p$ is the fluid pressure and $\mathrm{D}(\cdot) / \mathrm{D} t$ represents the material derivative. In the current work, the gravity and turbulence are neglected because the impact studied in this paper occurs over a time scale that is much shorter in duration than the time scale over which gravity acts on the flow. The flow field can be seen as laminar, since there is not enough time for turbulence to develop within such a short duration of time.

\section{Solution methods}

\subsection{Computational-Fluid-Dynamics approach}

90

The interDyMFoam solver from the open-source CFD library OpenFOAM (The OpenFOAM Foundation, 2017) is used to numerically solve the problems 


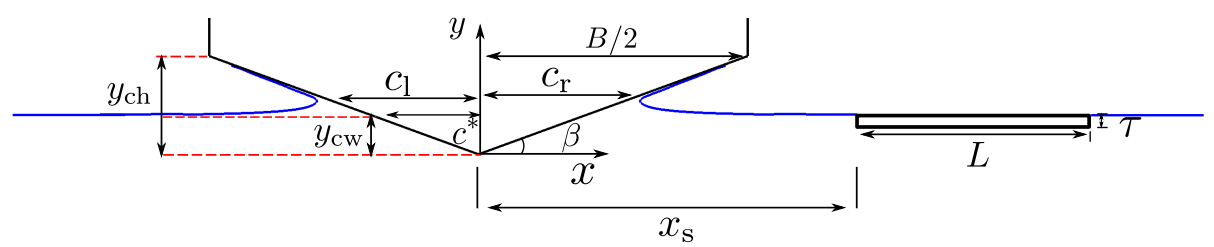

Figure 1: Schematic representation of the problem.

in this work. A finite-volume discretation is used with arbitrary LagrangianEulerian(ALE) formulation (Jasak, 2009) to allow for moving and deforming grids. The air-water interface is captured by using the volume-of-fluid (VOF) technique (Ubbink and Issa, 1999; Rusche, 2003). The free-surface evolution is calculated by numerical integration of the scalar transport equation Eq. (4) of the phase indicator variable $\alpha$.

$$
\frac{\mathrm{D} \alpha}{\mathrm{D} t}+\nabla \cdot\left[\mathbf{u}_{\mathrm{r}} \alpha(1-\alpha)\right]=0
$$

The second term of Eq. (4) is introduced to limit the numerical smearing of the fluid interface. $\mathbf{u}_{\mathbf{r}}$ is the free-surface compression velocity that is only active at the free-surface. For more details about the free-surface compression term, the reader are referred to Rusche (2003). The temporal discretization is achieved through an implicit Euler scheme. The convective term in Eq. (3) is integrated using the Gauss integration. A second-order central scheme is applied with the Sweby limiter (Sweby, 1984) to interpolate the variable from cell centre to cell face. The convective term in Eq. (4) is calculated using the same method except the Van Leer limiter is applied (Van Leer, 1974). For the diffusion term in Eq. (3), a second-order central scheme is used. An explicit non-orthogonal correction is applied when it is needed.

The computational domain is discretized using the snappyHexMesh application in OpenFOAM. A snapshot of the coarse mesh in a small domain is shown in Fig. 2. The size of the computational domain used for cases with semi-infinite ice in this study spans from $x \in[-5 B: 5 B]$ and $y \in[-5 B: 2 B]$. A domain dependence study has been conducted to determine the appropriate computational domain size (details can be found in Appendix A). The grids used in all 


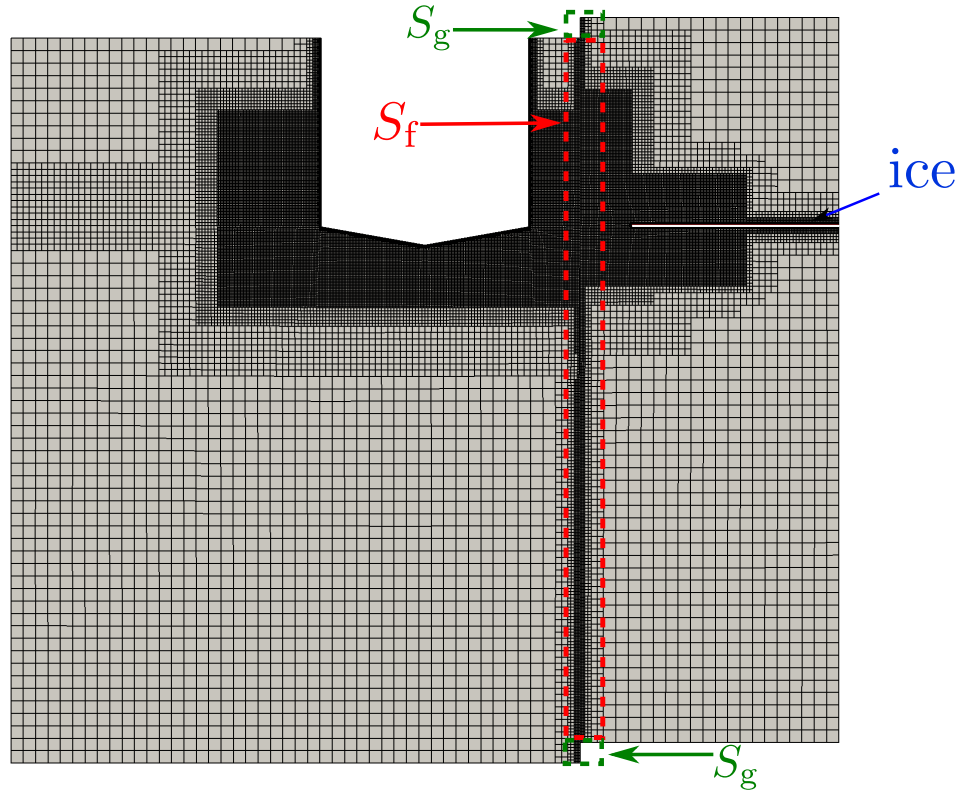

Figure 2: Illustration of the computational domain and the ACMI (Arbitrarily Coupled Mesh Interface) interface.

the cases have similar resolution. A grid refinement study is conducted to determine the grid resolution (details can be found in Appendix B). For example, the mesh for the case with semi-infinite ice, $2 \tau / B=0.01,2 x_{\mathrm{s}} / B=1.05$ and $\beta=10^{\circ}$ has 665,351 cells in total and 534 cells on the wedge bottom. Due to the different movement of the ice and the wedge, a sliding mesh technique, ACMI (Arbitrarily Coupled Mesh Interface), is used to account for the relative motion between the ice and the wedge. The computational domain is divided into two cell zones by the sliding mesh interfaces $\left(S_{\mathrm{f}}\right.$ and $\left.S_{\mathrm{g}}\right)$. The sliding-mesh interface is located at the mid-way between the wedge and the ice (highlighted in Fig. 2). The sliding-mesh interface enables the two cell zones to move with velocities. During the simulation, the cell zone that contains the wedge moves with the constant velocity while the sub-domain contains the ice is fixed in place. The solution of the flow variables at the sliding mesh interface $S_{\mathrm{f}}$ are interpolated based on the ratio of the face areas, while the zero gradient boundary conditions for both pressure and velocity are applied on the interface $S_{\mathrm{g}}$. A no-slip bound- 

applied on the wedge surface, the two side walls and bottom wall of the domain. On the top boundary, zero pressure and zero normal gradient for velocity are enforced. The Courant number is set to be less than 0.1 for all simulations.

\subsection{Theoretical model of water entry with floating ice} alised to account for the presence of an ice floe floating near the place of impact. At $t=0$ the wedge touches the water surface at a single point taken as the origin of the Cartesian coordinate system, $x=0$ (Fig. 3 (a)). The position of the wedge at $t>0$ is described by the equation $y=f(x)-h(t)$, where $f(x)=|x| \tan \beta, \beta$

is the wedge deadrise angle, and $h(t)$ is the penetration depth, $h(0)=0$. The ice floe and impact region are separated with an interval of free water surface, see Fig. 3 (b). In the Wagner model, the boundary conditions on the free surface, on the ice plate and in the impact region are linearized and imposed on the initial position of the water surface, $y=0$, see Fig. 3 (c). Both the ice floe and the impact region are approximated with flat plates of zero draft on the boundary of deep water, $y<0$. Before the impact, $t=-0$, the water and the ice floe are at rest. The theoretical model is formulated for freely floating ice. However, in this paper, the model is applied only to fixed ice in order to compare with results by the CFD approach.

In the theoretical model of this section, it is convenient to use the notation $\left(a_{2}, b_{2}\right)$ for the impact region and $\left(a_{1}, b_{1}\right)$ for the ice floe, see Fig. 3. $a_{2}, b_{2}$ correspond to $c_{l}, c_{r}$ in Fig. 1 and $a_{1}, b_{1}$ correspond to $x_{s}, x_{s}+L$. The contact region, $a_{2}(t)<x<b_{2}(t)$, expands in time, $a_{2}(0)=b_{2}(0)=0$. The coordinates of the edges of the contact region, $a_{2}(t)$ and $b_{2}(t)$, should be determined as part of the solution using the Wagner condition that the liquid displacements at these two points are finite. The small motion of the ice floe is described by the equation $y=h_{1}(t)+\alpha_{1}(t)\left(x-x_{c}\right)$, where $x_{c}=\left(a_{1}+b_{1}\right) / 2$ is the centre of the floe, $h_{1}(t)$ is the vertical displacement of this centre, and $\alpha_{1}(t)$ is the inclination angle of the floe (Fig. $3(\mathrm{~b})$ ). The functions $h_{1}(t)$ and $\alpha_{1}(t)$ are unknown in 
advance and should be determined as part of the solution.

The linearised problem of water entry is formulated and solved by using the displacement potential $\phi(x, y, t)$ and the complex displacement $W(z)=\phi_{x}-i \phi_{y}$, where $z=x+i y, \phi_{x}$ and $\phi_{y}$ are the horizontal and vertical components of the liquid displacement correspondingly. The pressure $p(x, y, t)$ in the liquid is given

The gravity and surface tension are not included in the Wagner model of water impact.

(a)

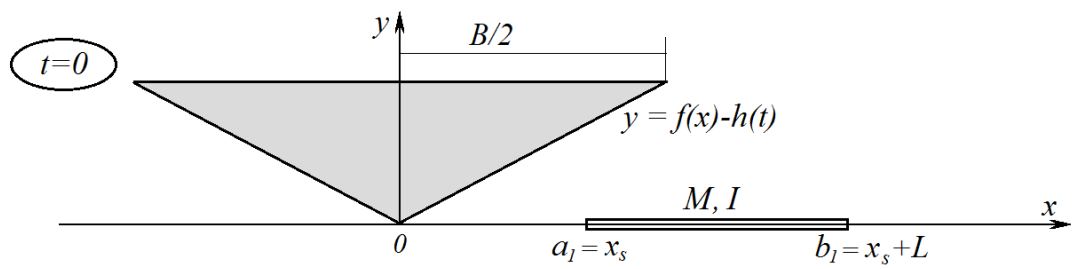

(b)

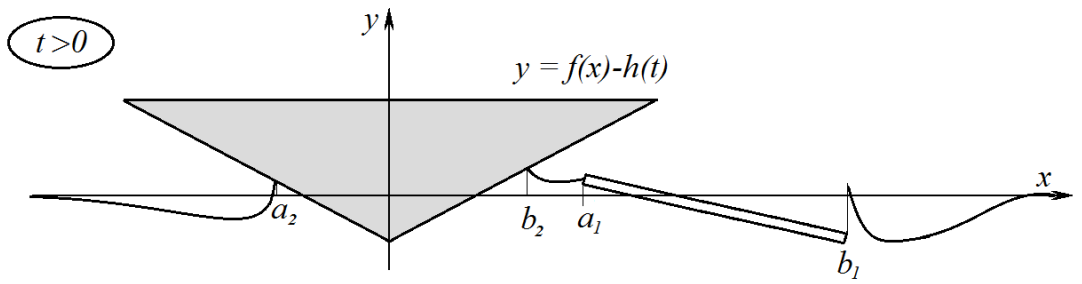

(c)

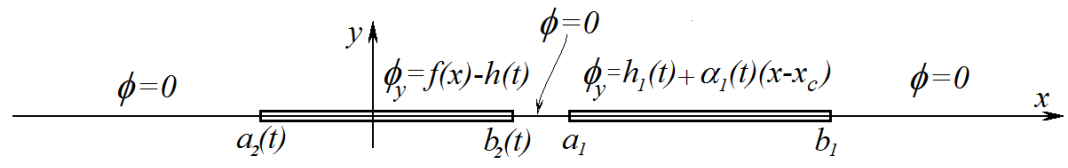

Figure 3: Sketch of the problem configuration with floating ice floe: (a) initial positions of the floe and the wedge, (b) physical plane of the water impact problem, (c) plane of the linearised hydrodynamic problem.

The complex displacement $W(z)$ is an analytic function in the flow region, $y<0$, and satisfies the boundary conditions $\phi_{y}=h_{1}(t)+\alpha_{1}(t)\left(x-x_{c}\right)$ on the ice plate, $a_{1}<x<b_{1}$, and $\phi_{y}=f(x)-h(t)$ in the impact region, $a_{2}(t)<x<b_{2}(t)$. On the interval of the free surface between the ice plate and the impact region, the dynamic boundary condition, $p(x, 0, t)=p_{a t m}$, provides $\phi=0$ after double 
integration in time and using the initial conditions. In particular, the liquid particles of the free surface can move only vertically, $\phi_{x}=0$ (Fig. 3 (c)).

The horizontal displacement, $\phi_{x}(x, 0, t)$, along the solid parts of the boundary is given by the Hilbert formula (Gakhov, 1966),

$\phi_{x}(x, 0, t) r_{j}(x)=\frac{1}{\pi} \sum_{n=1}^{2} \int_{a_{n}}^{b_{n}} \frac{\phi_{y}(\tau, 0, t) r_{n}(\tau) \mathrm{d} \tau}{\tau-x}+C_{1} \quad\left(a_{j}<x<b_{j}, j=1,2\right)$,

where $r_{1}(x)=-r(x), r_{2}(x)=r(x)$, and $r(x)=\left|\left(x-a_{1}\right)\left(x-b_{1}\right)\left(x-a_{2}\right)\left(x-b_{2}\right)\right|^{\frac{1}{2}}$. The constant $C_{1}$ in Eq. (5) is determined from the condition that $\phi(x, 0, t)=0$, where $b_{2}(t)<x<a_{1}$,

$$
\int_{a_{2}}^{b_{2}} \phi_{x}(x, 0, t) \mathrm{d} x=0
$$

and $\phi_{x}(x, 0, t)$ is given by Eq. (5). The functions $h_{1}(t)$ and $\alpha_{1}(t)$, which describe the motion of the ice floe, are governed by the linear equations

$$
M h_{1}^{\prime \prime}=F(t), \quad I \alpha_{1}^{\prime \prime}=Q(t),
$$

where $M$ is the total mass of the floe per unit width, $I$ is the moment of inertia of the floe, $I=M\left(b_{1}-a_{1}\right)^{2} / 12$, the hydrodynamic force $F(t)$ and torque $Q(t)$ are given by

$$
F(t)=\int_{a_{1}}^{b_{1}} p(x, 0, t) \mathrm{d} x, \quad Q(t)=\int_{a_{1}}^{b_{1}} p(x, 0, t)\left(x-x_{c}\right) \mathrm{d} x
$$
and the superscript " represents the second derivative with respect to time. Note that the gravity and buoyancy forces are not included in the model. Using the linearized Bernoulli equation, $p(x, 0, t)=-\rho \phi_{t t}(x, 0, t)$, the condition $\phi(x, 0, t)=0$, where $x=a_{1}$ and $x=b_{1}$, and integration by parts, we obtain

$$
\begin{aligned}
& F(t)=\rho \frac{\mathrm{d}^{2}}{\mathrm{~d} t^{2}}\left(\int_{a_{1}}^{b_{1}}\left(x-x_{c}\right) \phi_{x}(x, 0, t) \mathrm{d} x\right), \\
& Q(t)=\frac{\rho}{2} \frac{\mathrm{d}^{2}}{\mathrm{~d} t^{2}}\left(\int_{a_{1}}^{b_{1}}\left(x-x_{c}\right)^{2} \phi_{x}(x, 0, t) \mathrm{d} x\right) .
\end{aligned}
$$

The equations of motion (7) with account for (8) are integrated in time twice using the initial conditions, $h_{1}(0)=0, h_{1}^{\prime}(0)=0, \alpha_{1}(0)=0, \alpha_{1}^{\prime}(0)=0$, which 
leads to the following linear equations,

$$
M h_{1}=\rho \int_{a_{1}}^{b_{1}}\left(x-x_{c}\right) \phi_{x}(x, 0, t) \mathrm{d} x, \quad I \alpha_{1}=\frac{\rho}{2} \int_{a_{1}}^{b_{1}}\left(x-x_{c}\right)^{2} \phi_{x}(x, 0, t) \mathrm{d} x .
$$

Equations (6) and (9) form the linear system of three algebraic equations with respect to three unknown functions of time $C_{1}(t), h_{1}(t)$ and $\alpha_{1}(t)$. The coefficients and the right-hand sides of this system depend on time $t$ through the positions of the contact points $a_{2}(t)$ and $b_{2}(t)$ and the penetration depth $h(t)$. The coefficients are given by double integrals, which makes their evaluation challenging. Finally the motion of the contact points, $a_{2}(t)$ and $b_{2}(t)$, are determined by using the Wagner condition that the displacements are finite at these points and at the ends of the ice foe. This condition and the equation (5) yield that the right-hand side in (5) is equal to zero at $x=a_{2}(t)$ and at $x=b_{2}(t)$. The resulting system of five equations is linear with respect to $C_{1}(t)$, $h_{1}(t)$ and $\alpha_{1}(t)$ and nonlinear with respect to the positions of the contact points, $a_{2}(t)$ and $b_{2}(t)$. The system can be solved at each time instant independently because both the positions of the ice floe and the size of the contact region do not depend on the history of the flow but only on penetration depth $h(t)$. Therefore the time can be considered as a parameter of this system. Note that the solution of the problem also depends on the initial position of the floe and the shape of the body.

It is known that the Wagner model overestimates the forces acting on a body entering water. To correct the predictions of hydrodynamic loads, the MLM (Modified Logvinovich Model) can be used (Korobkin, 2004). In this model, the positions of the contact points, $a_{2}(t)$ and $b_{2}(t)$, and the displacement potential $\phi(x, y, t)$ are the same as in the Wagner model above. However, the pressure is calculated by the non-linear Bernoulli equation with a correction for the shape of the entering body.

For a wedge entering water at a constant speed and without any floating bodies nearby the Wagner model and MLM, as well as the fully nonlinear potential model, predict linear growth of the hydrodynamic force with time until the side walls of the wedge are fully wetted. Therefore the ratios of the theo- 


\begin{tabular}{l|c|c}
\hline$\beta$ & $2 \tau / B$ & $2 x_{\mathrm{s}} / B$ \\
\hline $10^{\circ}$ & 0.01 & $1.05,1.1,1.25,1.5,2.0,3.0$ \\
$20^{\circ}$ & 0.01 & $1.05,1.1,1.25,1.5,2.0,3.0$ \\
$30^{\circ}$ & 0.01 & $1.05,1.1,1.25,1.5,2.0,3.0$ \\
\hline
\end{tabular}

Table 1: Case matrix for the study on the effect of ice location.

220

retical forces calculated by different models are functions of the wedge deadrise angle only. The ratio for the fully nonlinear potential model and MLM is close to unity for a wide range of the deadrise angles. The ratio between the MLM prediction and the force provided by the Wagner model is equal to 0.839 for $\beta=10^{\circ}$. It is suggested to use this reduction coefficient also in the problems with floating ice. Even this simple scaling significantly improve the agreement between the theoretical predictions and the CFD force time history, as it will be shown in the next section.

\section{Results and discussion}

\subsection{Effect of the ice location}

A summary of the test cases for the investigation of the effect of the ice location is shown in table 1. A wedge with three different deadrise angles ( $\beta=$ $\left.10^{\circ}, 20^{\circ}, 30^{\circ}\right)$ is considered. For each deadrise angle, the location of the ice $2 x_{\mathrm{s}} / B$ is varied from very close to the wedge $\left(2 x_{\mathrm{s}} / B=1.05\right)$ to far away from the wedge $\left(2 x_{\mathrm{s}} / B=3\right)$. The ice thickness $2 \tau / B$ is set to 0.01 . The ice is considered to be semi-infinite. However, the semi-infinite ice can not be achieved exactly in the numerical model, the actual length of the ice modelled in the simulation is determined by conducting a domain dependence study (details can be found in Appendix A). It is found that $2 L / B=10$ is sufficient to model the effect of a semi-infinite ice for the purpose of this study.

\subsubsection{Hydrodynamic force}

The time history of the hydrodynamic force on the wedge is shown in Fig. 4. For all three deadrise angles, it is evident that as the wedge moves closer to the 
ice, the force increases. The increase in force is greatest as the jet root passes the chine. Moreover, the time to reach the maximum force is decreased. As discussed later in this section, this is related to the modified pile-up behaviour due to the presence of ice. The results from the theoretical model are very similar to the ones calculated by CFD before the wedge become fully wet. For clarity, the theoretical-model results are not shown in Fig. 4 (a)-(c). The maximum force from each case is nondimensionalized by the force of the ice-free CFD case and plotted in Fig. 4 (d). The result generated by the theoretical model is shown in solid line. As can be seen, it agrees very well with the results from the CFD calculations. Note that the theoretical line does not depend on the deadrise angle. As can be seen, the maximum force increases rapidly as the wedge move closer to the ice. As can be seen in Figures 4 (a)-(c), the force increases rapidly as the wedge moves closer to the ice. The maximum force is more than twice the force of the ice-free case for $2 x_{s} / B=1.1$ and 1.05 .

\subsubsection{Hydrodynamic pressure}

The pressure profile on the wedge surface at the instant of maximum force is shown in Fig. 5. As seen in Fig. 5, the pressure on the side of the wedge that is closer to the ice is much larger compared to the one for ice-free case. The ice also increases the pressure on the entire wedge.

In Fig. 6 - Fig. 8, the free-surface profile and the pressure-coefficient $\left(C_{p}\right)$ contour around the wedge are shown. Each column corresponds to a case with the ice in a different location. The plots in each row correspond to four different time instances. According to the Wagner theory, the jet root should reach the chine of the wedge around $y_{\mathrm{cw}} / y_{\mathrm{ch}}=2 / \pi \approx 0.64$ for symmetric wedge impact. In Fig. 6 - Fig. 8, for the case without ice, the spray root reaches the chine around $y_{\mathrm{cw}} / y_{\mathrm{ch}}=0.66$ which is similar to the Wagner theory. On the other hand, it can be seen that as the wedge moves closer to the ice the jet root rises faster due to the presence of ice, which results in the jet root reaching the chine earlier. In Fig. 6 - Fig. 8 , for the cases of $2 x_{\mathrm{s}} / B=1.05$, the chine becomes wet before $y_{\mathrm{cw}} / y_{\mathrm{ch}}=0.60$. Moreover, $C_{p}$ becomes much larger on the side of 


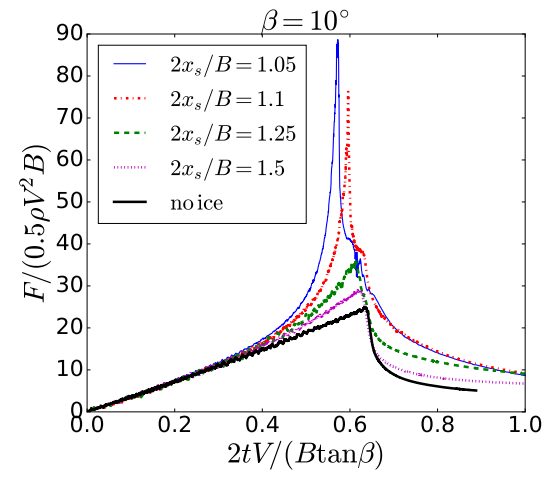

(a)

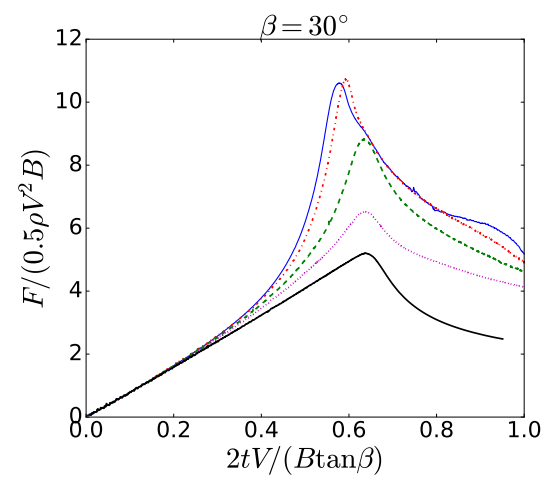

(c)

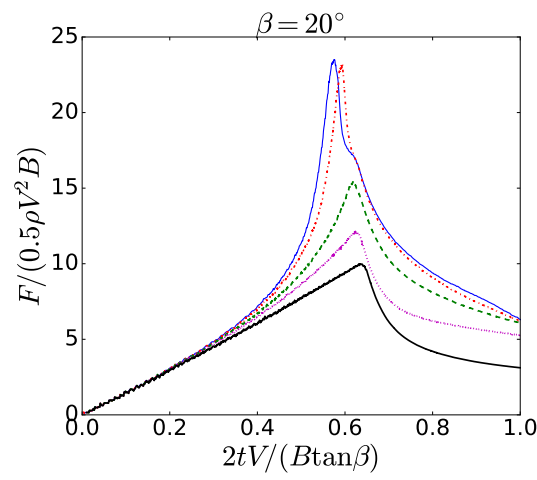

(b)

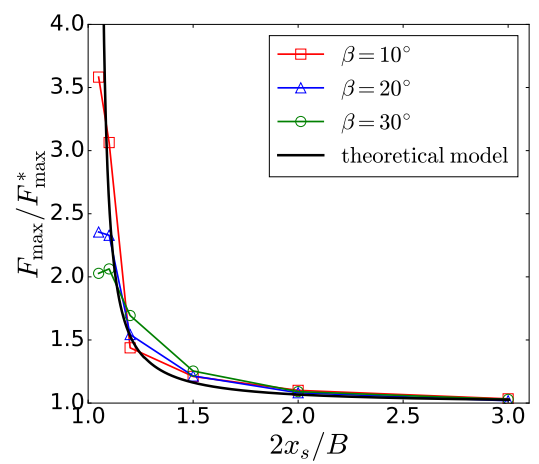

(d)

Figure 4: Hydrodynamic force time histories for cases with ice in different locations (a) $\beta=10^{\circ}$ (b) $\beta=20^{\circ}$ (c) $\beta=30^{\circ}$; (d) maximum force

the flow field where the ice is located. The faster rise-up of the water and the increase in $C_{p}$ explain the force trend shown in Fig. 4.

275

\subsubsection{Pile-up dynamics}

The pile-up phenomenon on each side of the wedge behaves differently as shown in Fig. 6 - Fig. 8. To examine this more closely, the pile-up coefficient $C_{\mathrm{w}}$ is plotted in Fig. 9. The jet root on each side of the wedge is tracked by locating the point of maximum pressure. It should be noted that this approach 


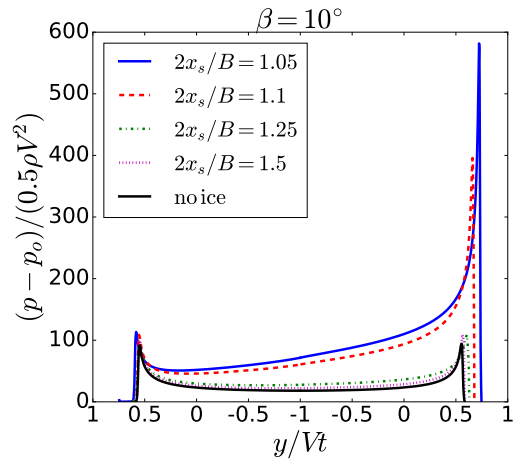

(a)

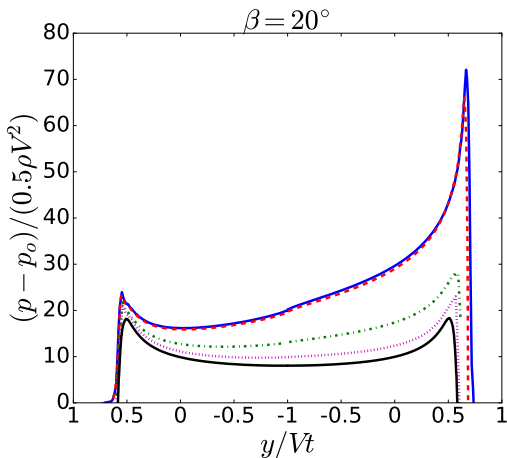

(b)

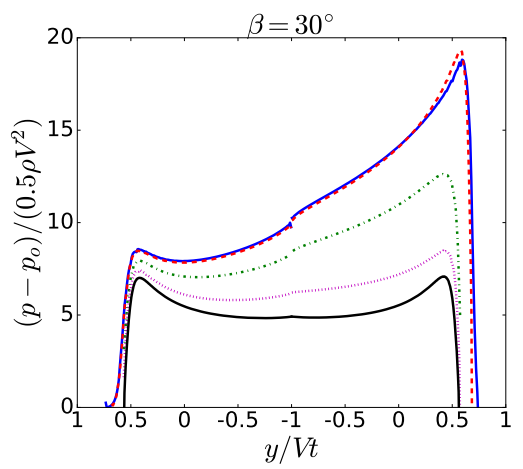

(c)

Figure 5: Pressure profile on the wedge at the instance of maximum force (a) $\beta=10^{\circ}$ (b) $\beta=20^{\circ}$ (c) $\beta=30^{\circ}$.

short distance between the point of maximum pressure and the jet root. As can be seen in Fig. 9, $C_{\mathrm{w}}$ remains the same for the both sides of the wedge for the ice-free case and is smaller than the value that Wagner theory predicts (Facci et al. (2015)). As the gap between the ice and the wedge decreases, the difference between the $C_{\mathrm{w}}$ for each side of the wedge becomes more apparent.

\subsection{Effect of the ice length}

A summary of the conditions for the investigation of the effect of the ice length is shown in table 2 . Wedge with deadrise angle $\beta=20^{\circ}$ is considered. 


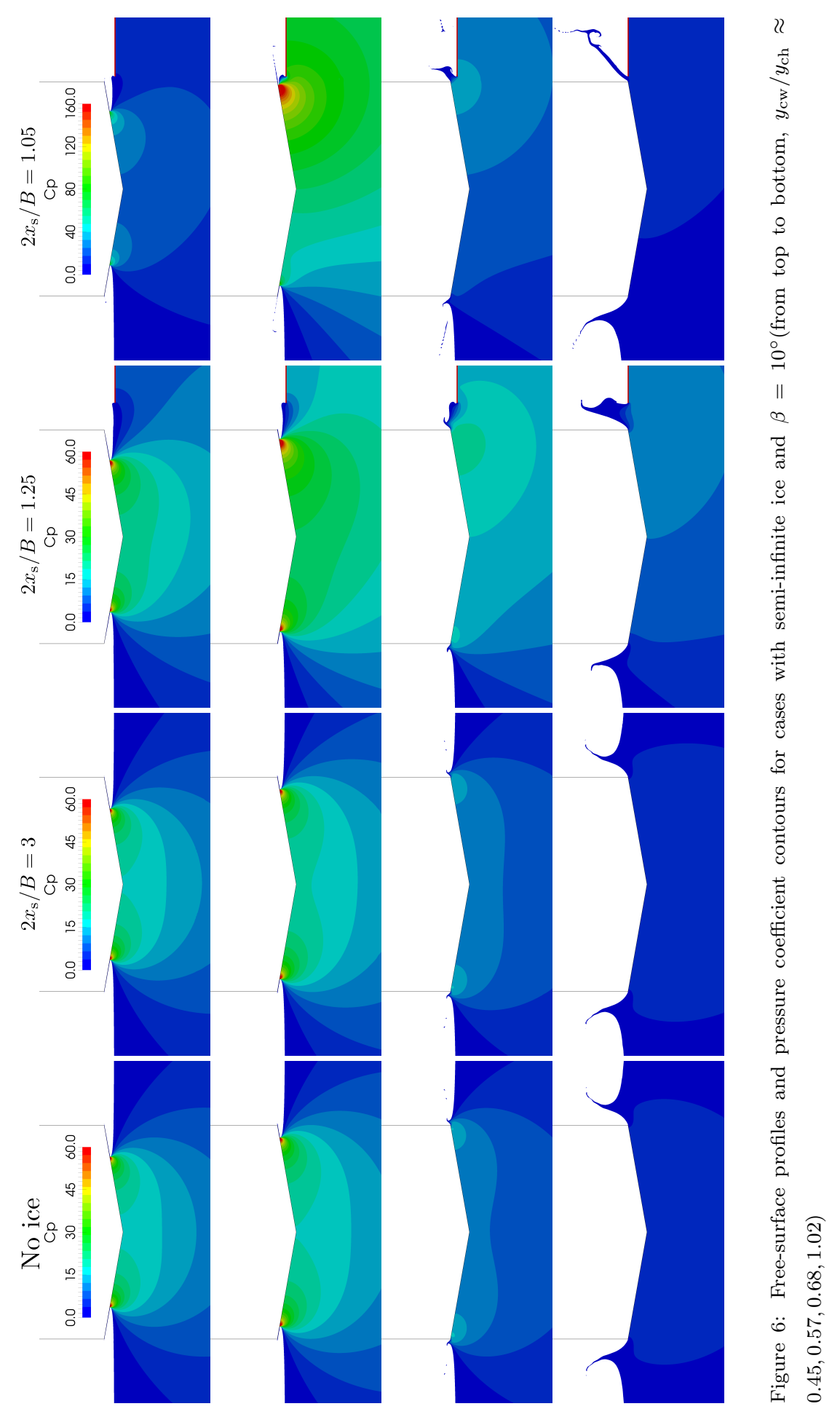




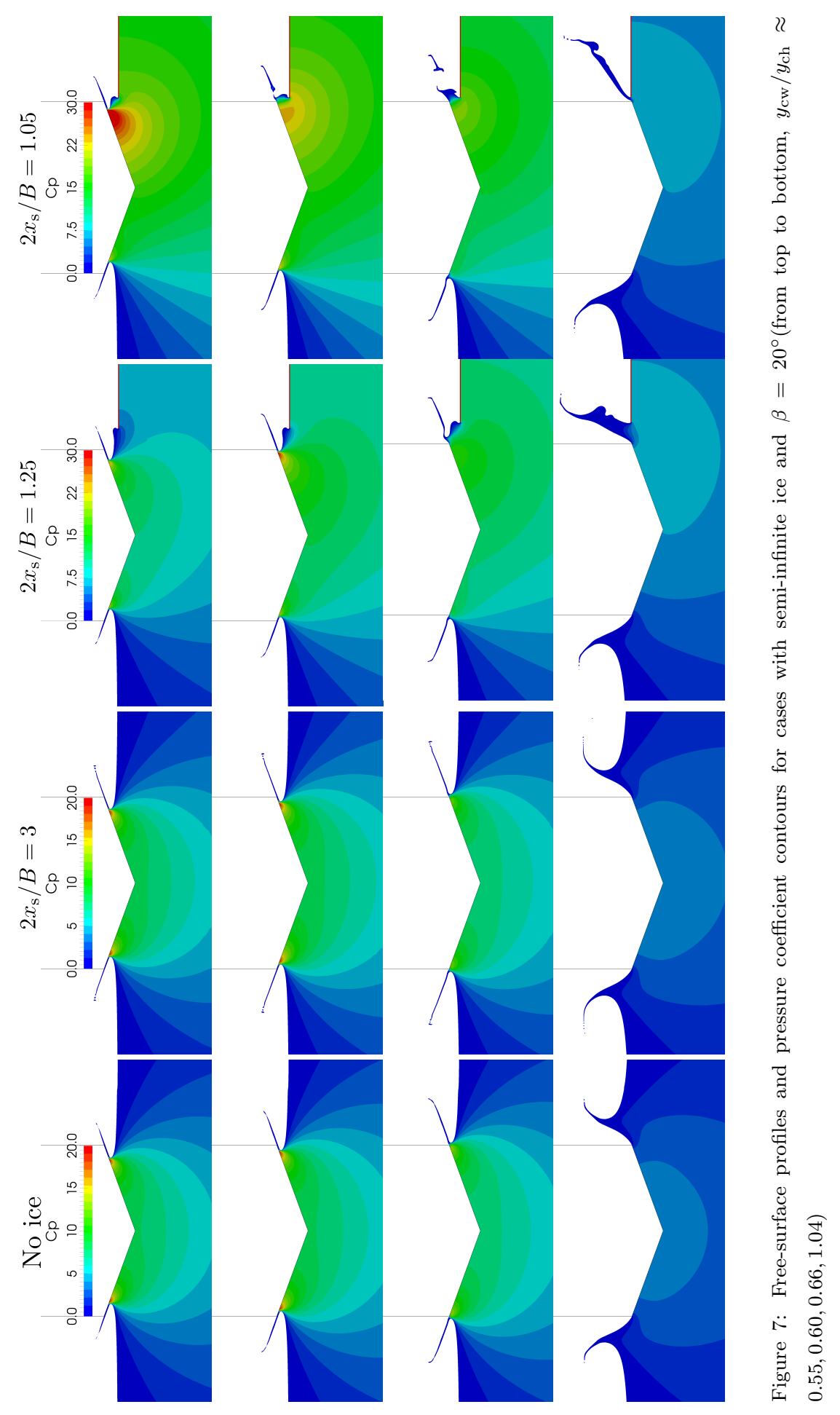




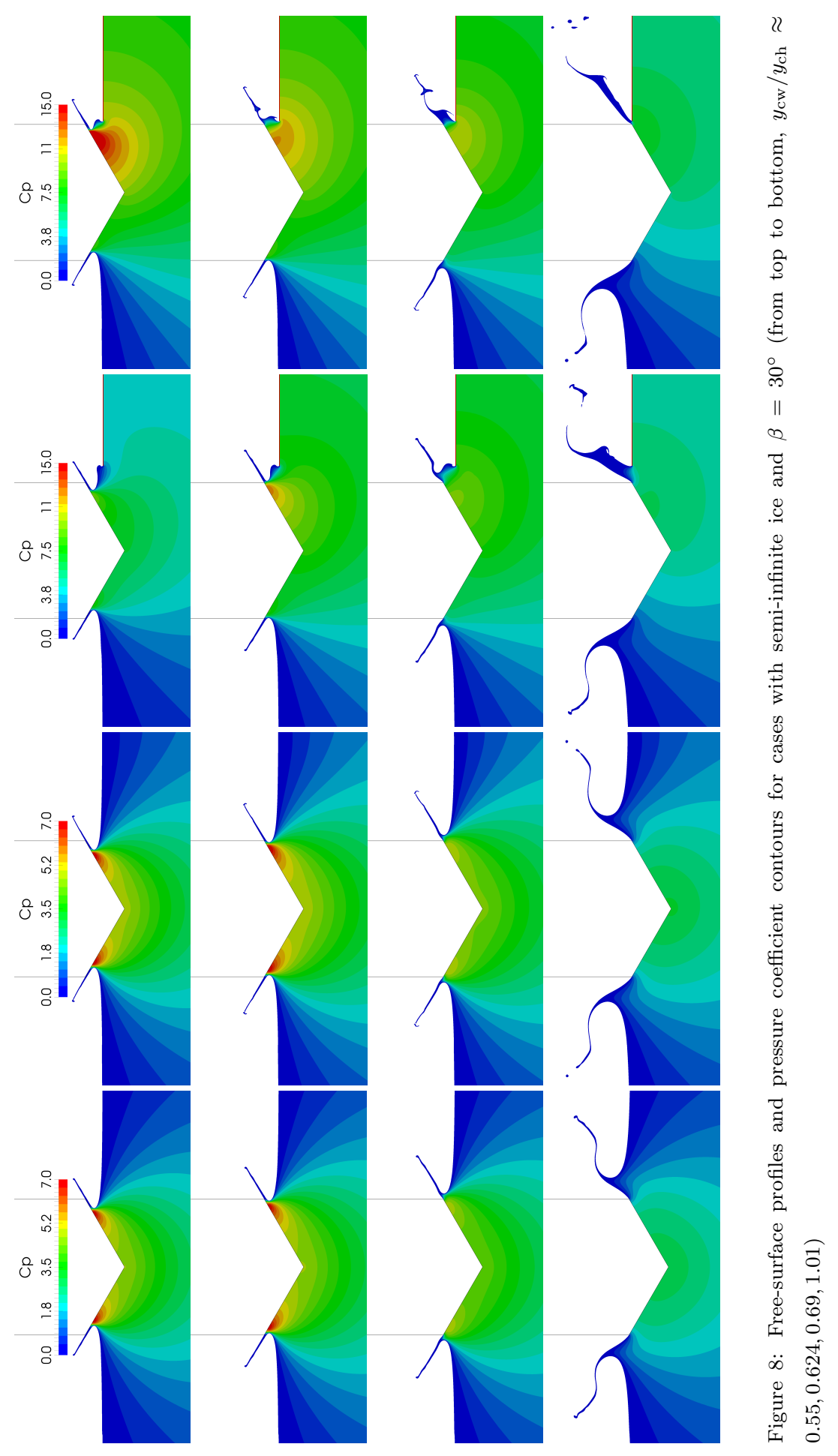



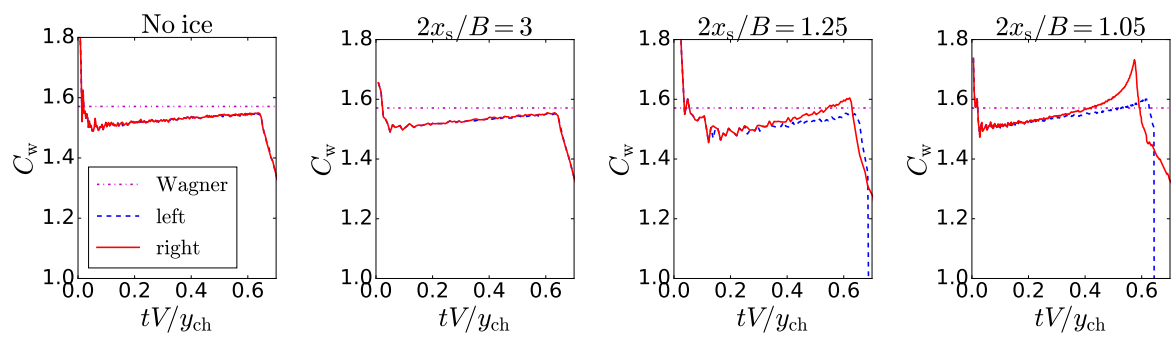

(a)
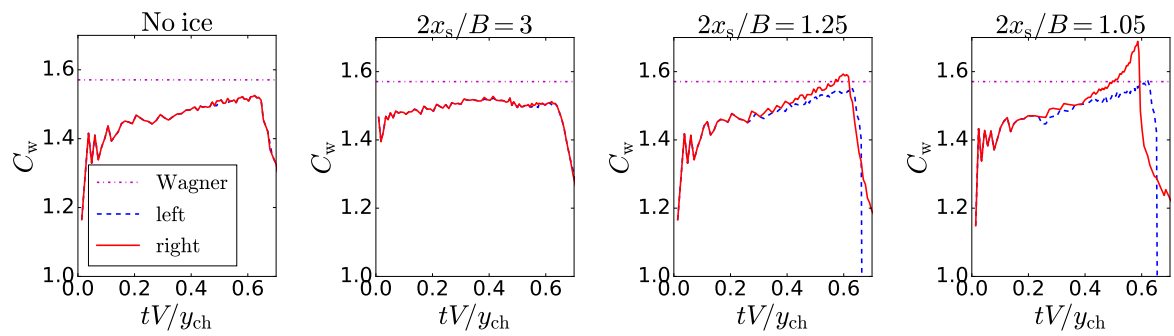

(b)
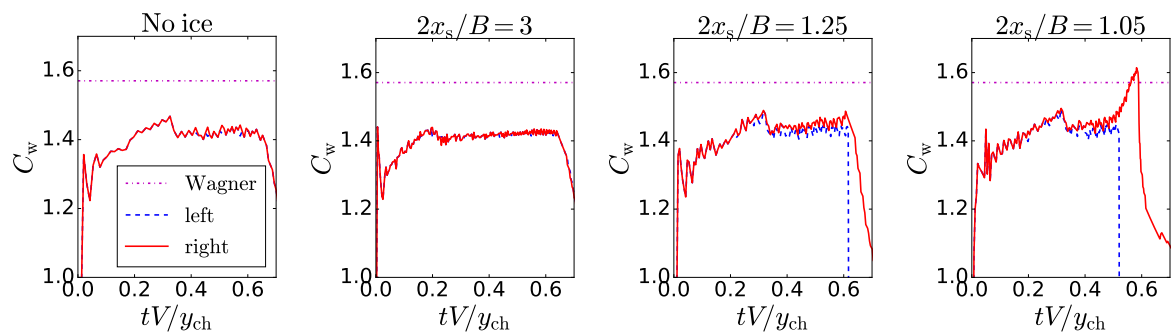

(c)

Figure 9: Pile-up coefficient time history for cases with semi-infinite ice (a) $\beta=10^{\circ}$ (b) $\beta=20^{\circ}$ (c) $\beta=30^{\circ}$ 


\begin{tabular}{l|c|c|c}
\hline$\beta$ & $2 \tau / B$ & $2 x_{\mathrm{s}} / B$ & $2 L / B$ \\
\hline $20^{\circ}$ & 0.01 & 1.1 & $0.5,1,2,3,6$ \\
\hline
\end{tabular}

Table 2: Cases for the study on the effect of ice length.

The location of ice relative to the wedge is fixed at $2 x_{\mathrm{s}} / B=1.1$, and the

\subsubsection{Hydrodynamic force}

The time history of the hydrodynamic force experienced by the wedge is shown in Fig. 10(a). It is shown that as the length of the ice increases, the vertical force experienced by the wedge increases and the time it takes to reach the maximum force decreases. The force time history for the cases with no ice and semi-infinite ice are also plotted in Fig. 10(a). The semi-infinite-ice result is that from Section 4.1 with $\beta=20^{\circ}, 2 x_{s} / B=1.1$. The results from the cases with no ice and semi-infinite ice are shown to be the lower and upper bounds.

The maximum force for cases with different ice length $2 L / B$ is plotted in soo Fig. 10(b). The maximum force $F_{\max }$ is nondimensionalized by the maximum force $F_{\max }^{*}$ of the ice-free case. As the ice length $2 L / B$ increases, the maximum force approaches that from semi-infinite-ice case. Even when the ice length is small $2 L / B=0.5$, there is about $30 \%$ increase in maximum force. The results from the theoretical model are also plotted in Fig. 10. As can be seen, although there are some differences, they generally agree with the CFD results.

\subsubsection{Hydrodynamic pressure}

The pressure profile on the wedge surface at the instant that the maximum force occurs is shown in Fig. 11. The pressure profile for the case without ice is also shown as reference. It is shown that as the ice becomes longer, the pressure on the side of the wedge near the ice increases substantially.

In Fig. 12, the free-surface profiles and the pressure-coefficient $\left(C_{p}\right)$ contours around the wedge are shown. Each column corresponds to a case with the ice of a different length. As seen in Fig. 12, as the ice becomes longer, the contour 


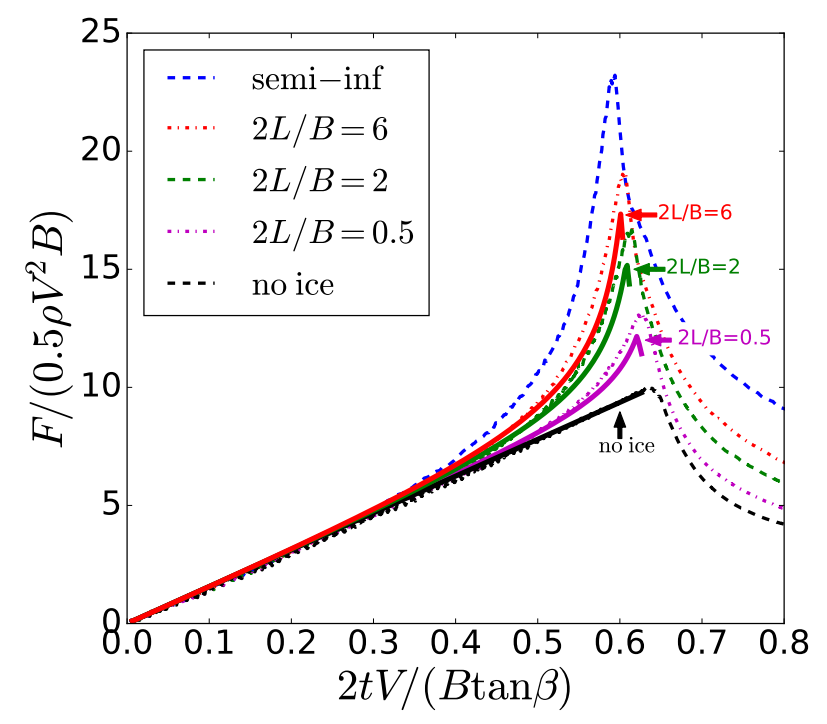

(a)

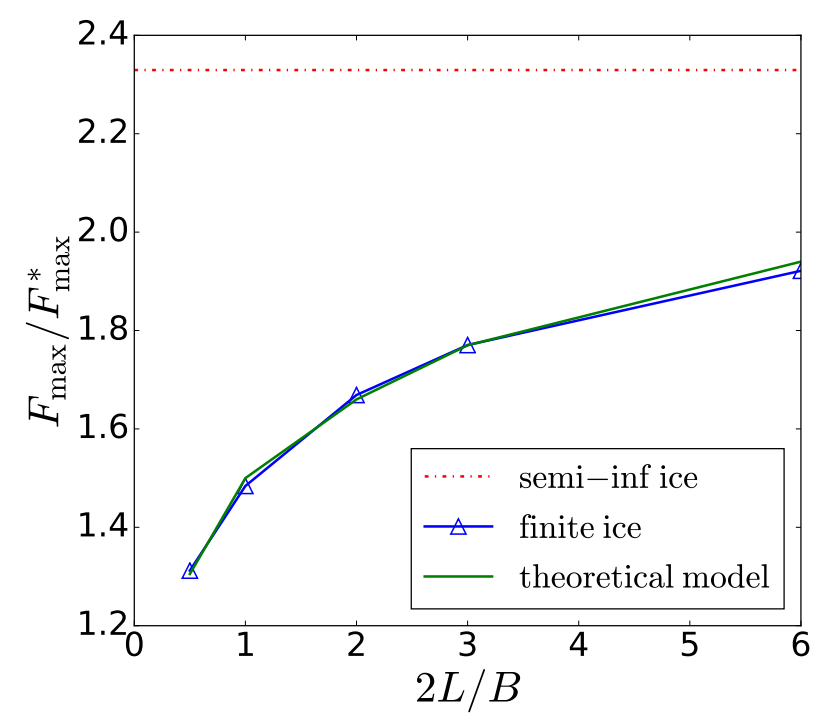

(b)

Figure 10: (a)Hydrodynamic force time histories (the results from the theoretical model are in thick solid lines and indicated by arrows and labels); (b) maximum force; for cases with different ice lengths $2 L / B$. 


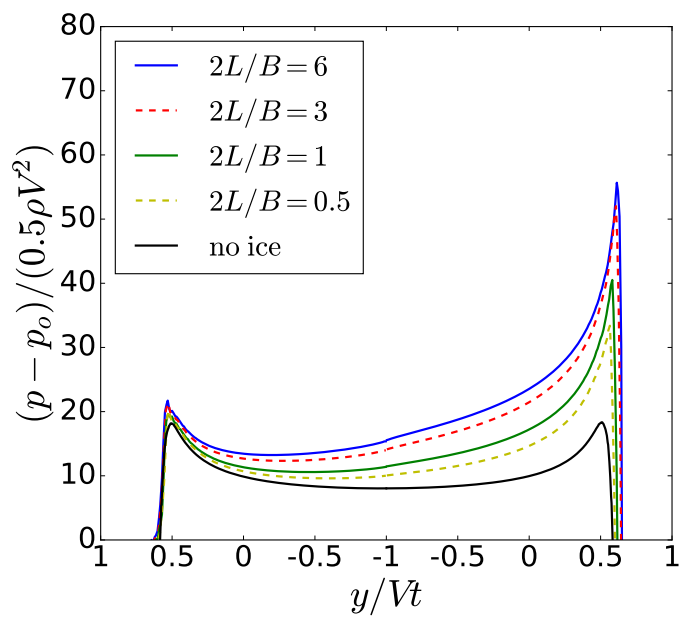

Figure 11: Pressure profile on the wedge at the instant of maximum force for cases with different ice length $2 L / B$

of $C_{p}$ becomes more asymmetric with a peak in the area between the ice and the wedge.

\subsubsection{Pile-up dynamics}

It can be see in Fig. 12, the pile-up phenomenon on each side of the wedge behaves differently. Similar to Section 4.1.3, the pile-up coefficient $C_{\mathrm{w}}$ is plotted in Fig. 13. As $2 L / B$ increases, the difference between the $C_{\mathrm{w}}$ for each side of the wedge becomes more apparent. $C_{\mathrm{w}}$ on the side of the wedge closer to the ice (right) increases faster than the one of left side and reaches a larger value.

\section{Conclusions}

In this work, the effect of ice on impact loads is studied using both CFD and a Wagner-type theoretical model. The canonical problem of a wedge entering water with a constant velocity near a single piece of fixed ice is considered. For the theoretical model, the two-dimensional Wagner model for water entry is generalised to account for the presence of the ice near the impact region. Within the CFD framework, the problem is solved by numerically integrating 


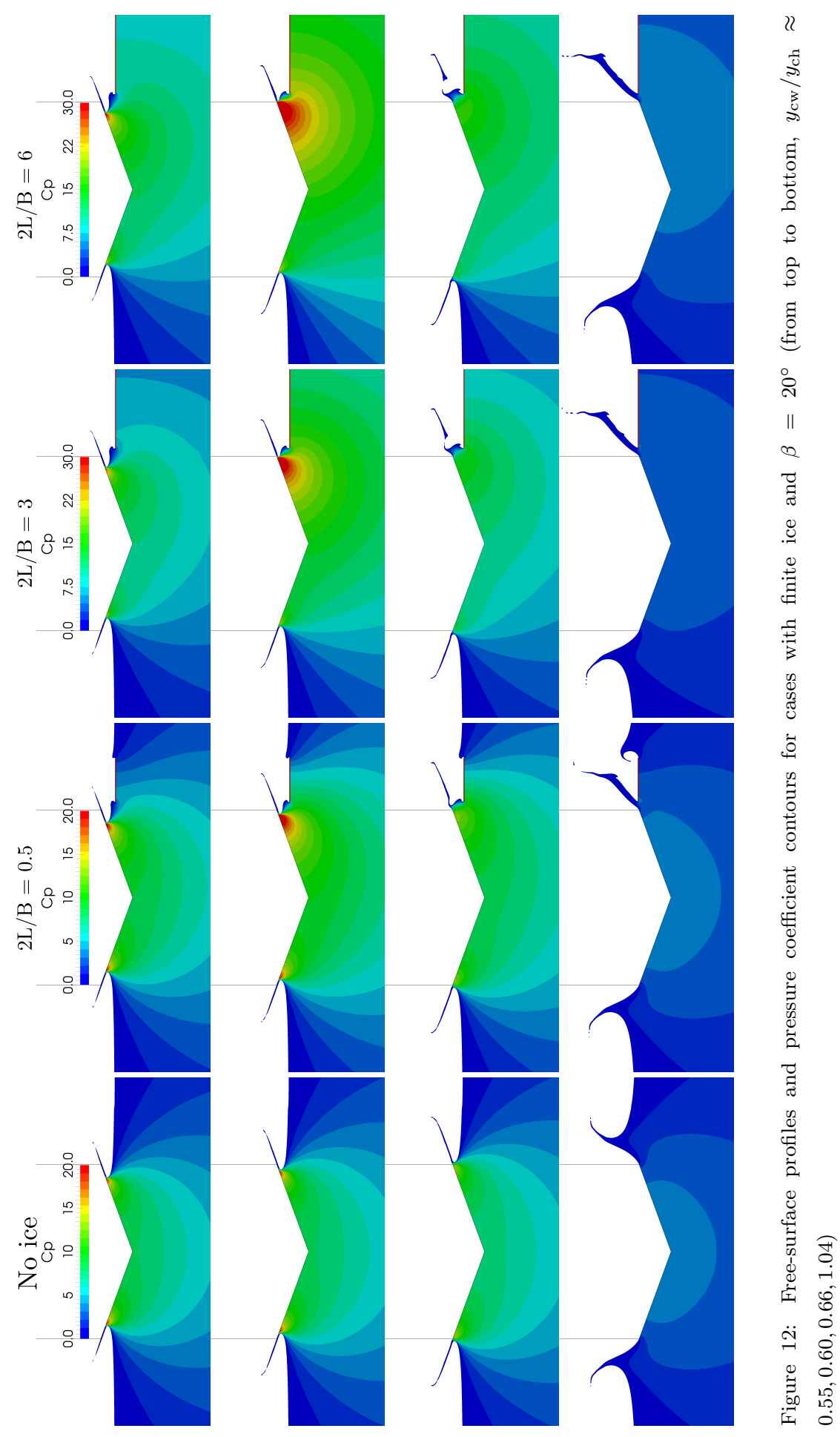



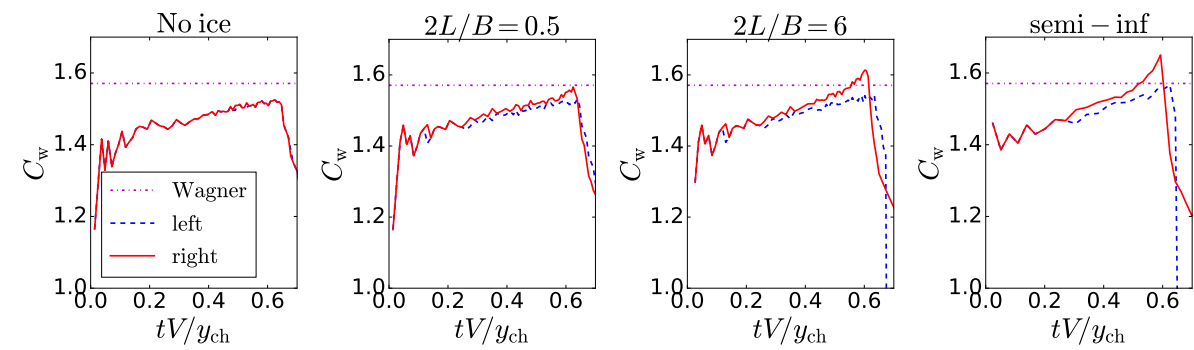

Figure 13: Pile-up coefficient time history

the Navier-Stokes equations and the VOF method is used to capture the freesurface. A sliding mesh technique is used to model the motion of the wedge while keeping the ice fixed in place. To study the effect of ice location, a single piece of semi-infinite ice is considered and the ice is placed at different distances away from the wedge. To study the effect of ice length, the distance between the ice and the wedge is fixed while the ice length is varied.

The hydrodynamic force, pressure profile and free-surface profile are examined to understand the effect of the ice. The maximum forces are also studied. The results calculated by the theoretical model have been compared with the CFD results. An excellent agreement has been shown in the comparison. The model predicts well the evolution of the vertical force acting on the wedge but overpredicts its magnitude. A simple correction for non-linear effects by the MLM significantly improves the theoretical prediction of the hydrodynamic loads. It is found that when the semi-infinite ice is placed very close to the wedge, the impact load can be increased more than twice compared to the one from a ice-free case. When the finite ice is considered, the impact load on the wedge is increased for about $30 \%$, even when the ice is small. The pile up of water increases due to the presence of ice. A pile-up coefficient is used to study the wetted width on each side of the wedge. It is found that the presence of ice increases the wetted width for both side of the wedge.

In this study, the ice floe is modelled as a rigid stationary plate, and the flow is two-dimensional. This model can be used to estimate the hydrodynamic 
forces acting on a body entering water near an ice floe. The actual forces are expected to be smaller than these estimates because of the motions of a real floe, its elastic deflection and three-dimensionality of the flow. The future work will be focused on improving the estimates taking into account more realistic characteristics of ice floes and their motions, as well as the three-dimensional effects on ice/water/body interaction. The sliding mesh technique of this paper can be readily extended to the problems with freely floating ice floes. Extension of the theoretical model to three-dimensional problems of water impact with floating ice is more challenging.

\section{Acknowledgement}

This work has been supported by the NICOP research grant "Vertical penetration of an object through broken ice and floating ice plate" N62909-17-1-2128, through Dr. Salahuddin Ahmed, and the ONR Grant N00014-16-1-2969 under the direction of Ms. Kelly Cooper. Any opinions, findings, and conclusions or recommendations expressed in this material are those of the authors and do not necessarily reflect the views of the Office of Naval Research.

The authors would like to thank the Isaac Newton Institute for Mathematical Sciences for the support and hospitality during the scientific programme "Mathematics of sea ice phenomena" in August-December 2017, when this study started. AK and TK acknowledge the support from Simons Foundation during their work within the programme at the Isaac Newton Institute for Mathematical Sciences.

\section{Appendix A. Domain dependence study}

To ensure that the computational domain is large enough so that the block375 age effect can be minimized, a domain dependence study is conducted. This study is also used to determine a sufficient ice length to model the semi-infinite ice for cases studied in Section 4.1 


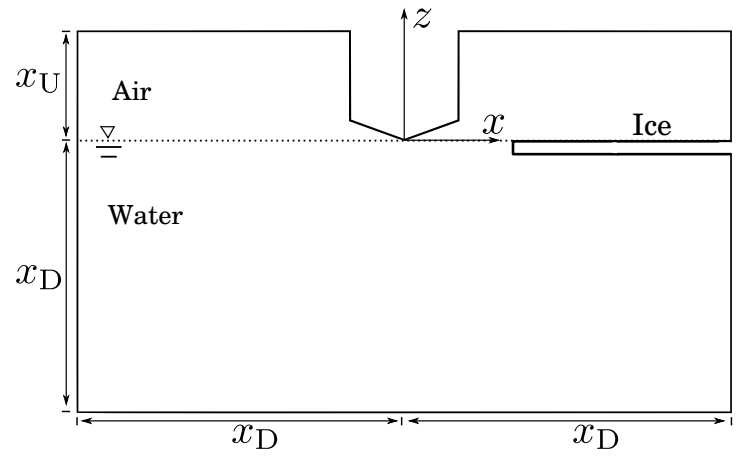

Figure A.1: sketch of the computational domain

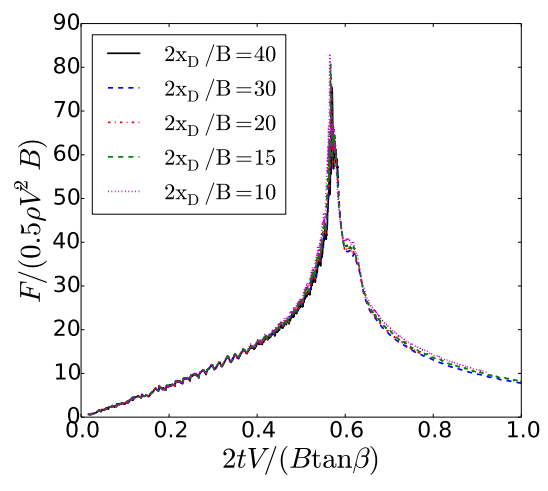

(a)

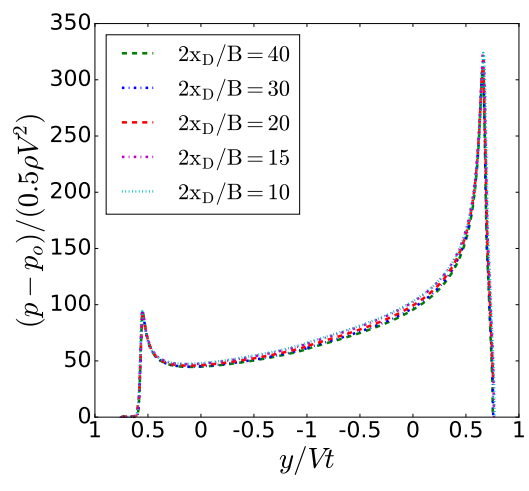

(b)

Figure A.2: (a) Force time histories (b) pressure profile on the wedge at the instant of maximum force

The case with a wedge of deadrise angle $\beta=10^{\circ}$ and a piece of semi-infinite ice $\left(2 x_{\mathrm{s}} / B=1.05,2 \tau / B=0.01\right)$ is selected for the domain dependence study. The sketch of the computational domain is shown in Fig. A.1. The distance between the top boundary and the calm water surface is fixed at $2 x_{\mathrm{U}} / B=4$. The distance $x_{\mathrm{D}}$ varies from $2 x_{\mathrm{D}} / B=10$ to $2 x_{\mathrm{D}} / B=40$.

The force time history and the pressure profile on the wedge at the instant of maximum force are plotted in Fig. A.2. As can be seen in Fig. A.2, the results of different domain size are mostly indistinguishable. Hence $2 x_{\mathrm{D}} / B=10$ is selected for all the cases in this paper. 


\begin{tabular}{l|c|c}
\hline Grid & $N$ & $N_{l}$ \\
\hline coarse & 179,424 & 266 \\
med & 347,857 & 380 \\
fine & 665,351 & 534 \\
vFine & $1,306,614$ & 762 \\
\hline
\end{tabular}

Table B.1: Summary of grids used in the grid refinement study.

\section{Appendix B. Grid refinement study}

A grid refinement study is conducted to ensure sufficient spacial resolution. The details of the grid are shown in table B.1, where $N$ is the total number of of Zhao and Faltinsen (1993). 


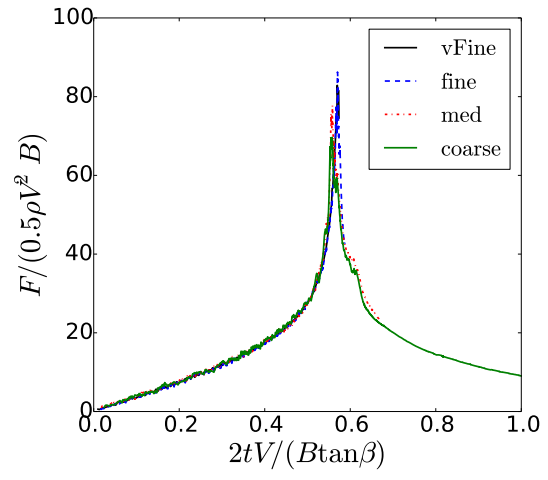

(a)

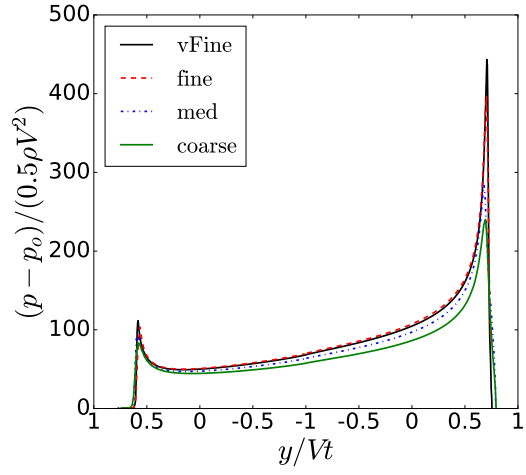

(b)

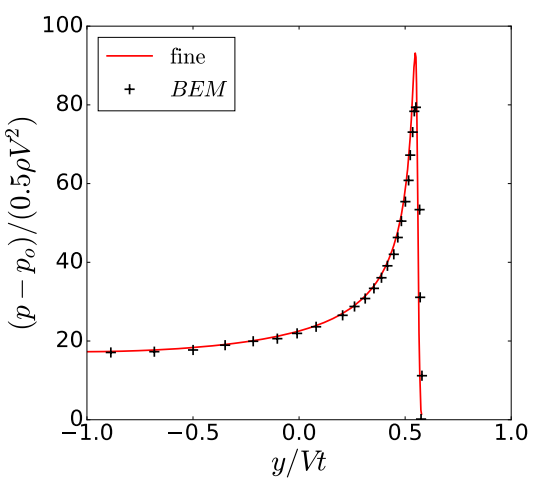

(c)

Figure B.1: (a) Force time histories (b) pressure profile on the wedge at the instant of maximum force (c) pressure profile for case with a 10 degree wedge and no ice (symbols are from Zhao and Faltinsen (1993)) 


\section{References}

Abrate, S., 2011. Hull slamming. Applied Mechanics Reviews 64, 060803.

Borgerson, S.G., 2008. Arctic meltdown: the economic and security implications of global warming. Foreign affairs, 63-77.

Facci, A.L., Panciroli, R., Ubertini, S., Porfiri, M., 2015. Assessment of pivbased analysis of water entry problems through synthetic numerical datasets. Journal of Fluids and Structures 55, 484-500.

Facci, A.L., Porfiri, M., Ubertini, S., 2016. Three-dimensional water entry of a solid body: A computational study. Journal of Fluids and Structures 66, $36-53$.

Fairlie-Clarke, A., Tveitnes, T., 2008. Momentum and gravity effects during the constant velocity water entry of wedge-shaped sections. Ocean Engineering $35,706-716$.

Farré, A.B., Stephenson, S.R., et al., 2014. Commercial Arctic shipping through the Northeast Passage: routes, resources, governance, technology, and infrastructure. Polar Geography 37, 298-324.

Gakhov, F., 1966. Boundary value problems, International series of monographs in pure and applied mathematics, Vol. 85. Pregamon Press, Oxford.

Hong, N., 2012. Research in Transportation Economics The melting Arctic and its impact on China's maritime transport. Research in Transportation Economics 35, 50-57.

International Maritime Organization (IMO), 2017. INTERNATIONAL CODE FOR SHIPS OPERATING IN POLAR WATERS (POLAR CODE). Technical Report. International Maritime Organization.

Jalalisendi, M., Osma, S.J., Porfiri, M., 2015. Three-dimensional water entry of a solid body: A particle image velocimetry study. Journal of Fluids and Structures 59, 85-102. 
Jasak, H., 2009. Dynamic mesh handling in openfoam, in: Proceeding of the 47th Aerospace Sciences Meeting Including the New Horizons Forum and Aerospace Exposition, Orlando, FL.

Judge, C., Troesch, A., Perlin, M., 2004. Initial water impact of a wedge at vertical and oblique angles. Journal of Engineering Mathematics 48, 279-303.

von Karman, T., 1929. The impact on seaplane floats during landing. Technical Notes 321, NACA .

Khabakhpasheva, T., Chen, Y., Korobkin, A., Maki, K., 2018. Water impact near the edge of a floating ice sheet, in: The 33rd International Workshop on Water Waves and Floating Bodies.

Khabakhpasheva, T., Korobkin, A., 2013. Elastic wedge impact onto a liquid surface: Wagner's solution and approximate models. Journal of Fluids and Structures 36, 32-49.

Korobkin, A., 1996. Water impact problems in ship hydrodynamics, in: Ohkusu, M. (Ed.), Advances in marine hydrodynamics.

Korobkin, A., 2004. Analytical models of water impact. European Journal of Applied Mathematics 15, 821-838.

Maki, K.J., Lee, D., Troesch, A.W., Vlahopoulos, N., 2011. Hydroelastic impact of a wedge-shaped body. Ocean Engineering 38, 621-629.

Mei, X., Liu, Y., Yue, D.K.P., 1999. On the water impact of general twodimensional sections. Applied Ocean Research 21, 1-15.

Piro, D., Maki, K., 2013. Hydroelastic analysis of bodies that enter and exit water. Journal of Fluids and Structures 37, 134-150.

Rusche, H., 2003. Computational fluid dynamics of dispersed two-phase flows at high phase fractions. Ph.D. thesis. Imperial College London (University of London). 
Scolan, Y.M., Korobkin, A., 2001. Three-dimensional theory of water impact. Part 1. Inverse Wagner problem. Journal of Fluid Mechanics 440, 293-326.

Semenov, Y.A., Iafrati, A., 2006. On the nonlinear water entry problem of asymmetric wedges. Journal of Fluid Mechanics 547, 231-256.

Su, B., Riska, K., Moan, T., 2010. A numerical method for the prediction of ship performance in level ice. Cold Regions Science and Technology 60, 177-188.

Sun, S., Wu, G., 2013. Oblique water entry of a cone by a fully three-dimensional nonlinear method. Journal of Fluids and Structures 42, 313-332.

Sweby, P.K., 1984. High resolution schemes using flux limiters for hyperbolic conservation laws. SIAM journal on numerical analysis 21, 995-1011.

The OpenFOAM Foundation, 2017. http://www.openfoam.org.

Thomson, J., Rogers, W.E., 2014. Swell and sea in the emerging arctic ocean. Geophysical Research Letters 41, 3136-3140.

Tveitnes, T., Fairlie-Clarke, A., Varyani, K., 2008. An experimental investigation into the constant velocity water entry of wedge-shaped sections. Ocean Engineering 35, 1463-1478.

Ubbink, O., Issa, R., 1999. A method for capturing sharp fluid interfaces on arbitrary meshes. Journal of Computational Physics 153, 26-50.

Van Leer, B., 1974. Towards the ultimate conservative difference scheme. ii. monotonicity and conservation combined in a second-order scheme. Journal of Computational Physics 14, 361-370.

Wagner, V.H., 1932. Über stoß-und gleitvorgänge an der oberfläche von flüssigkeiten. Zeitschrift für Angewandte Mathematik und Mechanik (ZAMM) 12 .

${ }_{480}$ Wu, G., Sun, H., He, Y., 2004. Numerical simulation and experimental study of water entry of a wedge in free fall motion. Journal of Fluids and Structures $19,277-289$. 
Zhao, R., Faltinsen, O., 1993. Water entry of two-dimensional bodies. Journal of fluid mechanics 246, 593-612.

${ }_{485}$ Zhou, Q., Peng, H., Qiu, W., 2016. Numerical investigations of ship-ice interaction and maneuvering performance in level ice. Cold Regions Science and Technology 122, 36-49. 